\title{
A comparative study of digoxigenin, 2,4-dinitrophenyl, and alkaline phosphatase as deoxyoligonucleotide labels in non-radioisotopic in situ hybridisation
}

Richard Bright Renal Unit, Southmead Hospital,

Westbury-on-Trym Bristol BS10 5NB, UK S J Harper

Department of Nephrology, Leicester General Hospital, Gwendolen Road, Leicester LE5 4PW, UK

E Bailey

J Feehally

Oswel Laboratory, Medical and Biological Sciences Building,

University of

Southampton, Boldrewood, Bassett

Crescent East, Southampton SO16 7PX, UK

C M McKeen

A S J Stewart

T Brown

\section{Department of} Pathology, University of Leicester, Clinical Sciences Building, Leicester Royal Infirmary, Leicester, UK

J H Pringle

Correspondence to: Dr Harper.

Accepted for publication 13 May 1997

\begin{abstract}
Aim-To determine the optimum form of labelling and the most efficient reporter molecule for non-radioisotopic in situ hybridisation (ISH).

Methods-Nine deoxyoligonucleotides complementary to histone mRNA were synthesised and labelled either enzymatically or during solid-phase synthesis with the reporter molecules digoxigenin, 2,4dinitrophenyl (DNP), or alkaline phosphatase. Pooled deoxyoligonucleotide cocktails were then used in nonradioisotopic ISH detection of histone mRNA in human tonsil. Hybrid detection was by nitroblue tetrazoleum/5-bromo-4chloro-3-indolyl phosphate colorimetric development.
\end{abstract}

Results-The use of a spacer in $3^{\prime}$ enzymatic labelling and when labelling with alkaline phosphatase significantly increased ISH signal. The 3 ' and 5' labelling of oligonucleotides with triple DNP groups during solid-phase synthesis produced the strongest signal as determined by the highest cell signal intensity and shortest development time.

Conclusions-3' and 5' solid-phase labelling with triple DNP groups produced the best labelling for non-isotopic ISH using deoxyoligonucleotide cocktails.

$(\mathcal{A}$ Clin Pathol 1997;50:686-690)

Keywords: digoxigenin; 2,4-dinitrophenyl; alkaline phosphatase; in situ hybridisation

In situ hybridisation (ISH) oligonucleotide probes may be labelled with radioactive or non-radioactive reporter groups. After the initial description of ISH in $1969^{1}$ radioactive labelling became the norm, allowing sensitive semiquantitative detection of nucleotide sequences. However the use of such labels $\left({ }^{3} \mathrm{H}\right.$, $\left.{ }^{32} \mathrm{P},{ }^{35} \mathrm{~S},{ }^{125} \mathrm{I}\right)$ is hazardous, expensive, and time consuming, furthermore these labels have a limited shelf life. In contrast, the use of non-radioactive reporter groups (biotin, fluoroscein, digoxigenin, dinitrophenyl) is simple and safe, costs are comparable, scaling up is easy, development time short, and shelf life long. Non-radioisotopic ISH can also be semiquantitative. ${ }^{23}$ The main disadvantage remains the relatively lower sensitivity of non-radioactive reporter groups. The sensitivity of non-radioisotopic ISH using oligonucleotide probes can be increased in a number of ways: using oligonucleotides that form efficient hybrids, ${ }^{4}$ using cocktails of a number of non-overlapping oligonucleotides to the same target species, and by using multiple reporter groups per oligonucleotide. ${ }^{5}$ This study considers the last of these options.

Biotin has frequently been used as a non-radioactive reporter molecule. However, it has a number of drawbacks including the presence of high levels of endogenous biotin in some normal tissues. Fluorescein has been used as an oligonucleotide label, as a hapten rather than a fluorochrome, ${ }^{6}$ but in our experience multiple additions of this reporter group results in unacceptable background staining (unpublished data). The plant steroid digoxigenin is becoming increasingly used to label oligonucleotides for ISH protocols and the reporter molecule 2,4-dinitrophenyl (DNP) has been shown to give comparable results to that of biotin, fluorescein, and digoxigenin when bound to filters. ${ }^{78}$ The technology also exists to label directly the oligonucleotides with enzymes-for example, alkaline phosphatase, although the chemistry is time consuming. ${ }^{9}$

Our experience suggests that hybridisation results on crude filters may not translate to ISH as some labels produce significant background staining when applied to tissue sections. The aim of this work was to develop an oligonucleotide cocktail with a range of different labels to assess the most sensitive labelling-detection system for use in non-radioisotopic ISH. We chose to study the expression of histone mRNA in human tonsils. This is a model system for the detection of native human mRNA in fresh human tissue. It accurately identifies cells in $S$ phase of the cell cycle ${ }^{10}$ and we have found this probe cocktail robust and reliable. ${ }^{10}{ }^{11}$ In human tonsil the probe cocktail identifies $S$ phase cells in the light and dark zones of the germinal centres, within the basal layers of the epithelium, and in the interfollicular zone. Owing to the limitations of biotin and fluorescein, we chose to study the labels digoxigenin, DNP, and alkaline phosphatase.

Aliquots of unlabelled oligonucleotides were labelled enzymatically with digoxigenin-11dUTP or DNP-dUTP using terminal nucleotidyl transferase, both with and without a nucleotide spacer (dATP). In addition, batches 
Table 1 Enzymatic deoxyoligonucleotide labelling

\begin{tabular}{|c|c|c|c|}
\hline Without nucleotide spacer & & With nucleotide spacer & \\
\hline $\begin{array}{l}\text { Nanopure } \mathrm{H}_{2} \mathrm{O} \\
\text { Probe cocktail }(500 \mathrm{ng}) \\
10 \mathrm{mM} \mathrm{MnCl} \\
1 \mathrm{mM} \text { digoxigenin-11-dUTP } \\
1 \mathrm{mM} \text { DNP-dUTP } \\
15 \\
1 \mathrm{mM} \text { dATP } \\
1.2 \mathrm{M} \text { Na cocodylate } \\
2 \mathrm{mM} \text { 2-deoxyuridine-5- tetrasodium } \\
\text { triphosphate } \\
\text { Terminal deocynucleotidyl transferase }\end{array}$ & $\begin{array}{l}1.6 \mu \mathrm{l} \\
- \\
10 \mu \mathrm{l} \\
5-\mu \mathrm{l} \\
4 \mu \mathrm{l}\end{array}$ & 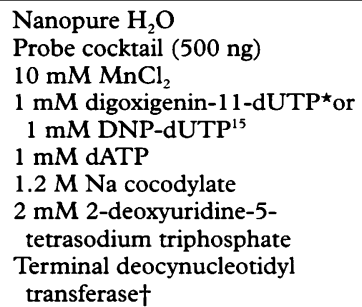 & $\begin{array}{l}1.6 \mu \mathrm{l} \\
3.3 \mu \mathrm{l} \\
10 \mu \mathrm{l} \\
5 \mu \mathrm{l} \\
4 \mu \mathrm{l}\end{array}$ \\
\hline
\end{tabular}

^220582, Boehringer Mannheim; †27-0730-02, Pharmacia.

of probe were labelled by chemical synthesis with digoxigenin (three groups at the $5^{\prime}$ end, one at the $3^{\prime}$ end); DNP (triple groups at both $3^{\prime}$ and $5^{\prime}$ ends (previous work has suggested that triple DNP groups give optimal signal $\left.{ }^{12}\right)$ ); or alkaline phosphatase at the 5 ' end (with and without a hydrophilic spacer).

Each batch of labelled probe was then optimised individually for concentration, stringency, antibody label detection, and colorimetric development time. The batches were compared in parallel experiments: one in which each slide was incubated until optimal signal was attained (experiment 1), the other in which a fixed development time was used (one hour; experiment 2). Preliminary experiments indicated that this development time would allow comparisons using subsaturated signal.

\section{Materials and methods}

Tonsils from elective tonsillectomy cases were cut into $0.5 \times 1 \mathrm{~cm}$ sections at removal and frozen in liquid nitrogen cooled isopentane. Subsequently all specimens were stored in liquid nitrogen before sectioning.

\section{PROBE AND PROBE LABELLING}

Deoxyoligonucleotides complementary to the histone genes $\mathrm{H} 2 \mathrm{~b}, \mathrm{H} 3$, and $\mathrm{H} 4$ were used. Final probe cocktails contained nine oligonucleotides, three for each gene, as previously described. ${ }^{1011}$ All deoxyoligonucleotides were 30 bases long, this length has been established as a practical compromise between hybrid stability, hybrid specificity, cost of synthesis and purification, and tissue penetration efficiency. ${ }^{14}$

Digoxigenin and DNP labelling was accomplished either enzymatically (unlabelled sequences were kindly donated by Pathway Services Ltd, Leicester, UK) or at synthesis. Oligonucleotides were labelled with alkaline phosphatase both directly and separated by a hexaethylene glycol spacer. The hexaethylene glycol monomer was prepared according to the method of Durand et al. ${ }^{15}$

Enzymatic 3' labelling was achieved using a method adapted from Pringle $e t a l^{16}$ either with or without a nucleotide spacer (dATP) (table 1). The labelling reaction took place at $37^{\circ} \mathrm{C}$ for two hours. The DNP deoxyuridine triphosphate $(5-[2,4$ dinitrophenylaminopentylcarbonnylarninopropargyl ] - 2 - deoxyuridine - 5tetra-sodium triphosphate) was synthesised by established procedures. ${ }^{17}$
Chemical synthesis and solid-phase chemical labelling was performed using established chemical methods (OSWEL DNA Service, Southampton, UK).

\section{EVALUATION OF OLIGONUCLEOTIDES}

Non-radioisotopic ISH

The protocol for non-radioisotopic ISH was adapted from that previously reported. ${ }^{2} 3111819$ RNAse free reagents and glassware (diethylpyrocarbonate (DEPC) treated; Sigma, UK D5758) were used throughout. Sequential $8 \mu \mathrm{M}$ sections were cut at $-20^{\circ} \mathrm{C}$ onto silane coated slides and fixed in freshly prepared $4 \%$ paraformaldehyde for 10 minutes at $4^{\circ} \mathrm{C}$. Slides were washed in phosphate buffered saline (PBS)/DEPC $3 \times 5$ minutes. Probe cocktail $(15 \mu \mathrm{l})$ was added to the tissue and a coverslip applied. Hybridisation took place at $37^{\circ} \mathrm{C}$ for two hours. Hybridisation solution contained $500-2000 \mathrm{ng} / \mathrm{ml}$ of oligonucleotide probe, $600 \mathrm{mM} \mathrm{NaCI}, 50 \mathrm{mM}$ Tris $\mathrm{pH} \mathrm{7.5}$, $0.2 \%$ bovine serum albumin, $1 \%$ sodium dodecyl sulphate, $1 \%$ polyvinylpyrrolidone (40 kDa), 1\% Ficoll (400 kDa), 0.1\% sodium pyrophosphate, $5 \mathrm{mM}$ EDTA, $10 \%$ dextran sulphate, and $30 \%$ formamide.

Post-hybridisation washes were as follows: $2 \times$ standard saline citrate solution (SSC) $/ 30 \%$ formamide $\left(2 \times 10\right.$ minutes at $\left.37^{\circ} \mathrm{C}\right) ; 2 \times \mathrm{SSC}$ at room temperature ( $2 \times 10$ minutes); and 15 minutes in blocking solution at room temperature. (SSC consisted of $150 \mathrm{mM} \mathrm{NaCl}, 15 \mathrm{mM}$ trisodium citrate $\mathrm{pH} 7.0$; blocking solution consisted of TBS, $0.1 \%$ Triton-X100, 3\% bovine serum albumin.) Slides were incubated with alkaline phosphatase labelled detection antibodies for 30 minutes. Either polyclonal anti-digoxigenin $\mathrm{F}(\mathrm{ab})_{2}$ antibody (1093274; Boehringer Mannheim, Germany) diluted $1 / 600$ in blocking solution, or polyclonal anti-DNP $\mathrm{F}(\mathrm{ab})_{2}$ antibody (donated by Dako, High Wycombe, UK). Specimens were then washed in blocking solution $(2 \times 5$ minutes $)$, immersed in buffer 3 (0.1 M Tris $\mathrm{HCI}$ pH 9.5, $0.1 \mathrm{M} \mathrm{NaCI}, 0.05 \mathrm{M} \mathrm{MgCl})(1 \times 10 \mathrm{~min}-$ utes), and then in substrate solution $(44 \mathrm{ml}$ nitroblue tetrazoleum (NBT; Sigma, $75 \mathrm{mg} / \mathrm{ml}$ in $70 \%$ dimethylformamide), $33 \mathrm{ml} \mathrm{5}$-bromo4-chloro-3-indolyl phosphate (BCIP; Sigma, $50 \mathrm{mg} / \mathrm{ml}$ in dimethylformamide) in $10 \mathrm{ml}$ buffer 3). After development all slides were washed in running tap water for 10 minutes, counterstained with Mayer's haematoxylin and mounted in aqueous mounting medium.

All slides and probe cocktails were coded. Slides were stopped (with frequent viewing) after development of optimal signal (experiment 1 ) or after one hour (experiment 2). In experiment 2 cell signal intensity of the first 50 histone mRNA positive cells visualised at high power ( $\times 40$ objective) while scanning the long axis of the same identified germinal centre was measured using a Nikon Optiphot microscope and an image analysis system using a Hitachi TK-1280E Video Camera, an Apple-Mac $7100 / 80 \mathrm{AB}$, and NIH-Image software.

Comparisons between probes could therefore be made both in terms of cell signal intensity and in optimal development time. 
Table 2 Development times

\begin{tabular}{|c|c|c|c|c|}
\hline Label & Probe labelling & $\begin{array}{l}\text { Optimal } \\
\text { probe } \\
\text { ng/ml* }\end{array}$ & $\begin{array}{l}\text { Time to } \\
\text { optimal } \\
\text { signal } \\
\text { (hours) }\end{array}$ & Background $\dagger$ \\
\hline Digoxigenin & $\begin{array}{l}\text { Enzymatic 3' without } \\
\text { spacer }\end{array}$ & 500 & 18 & 0 \\
\hline Digoxigenin & Enzymatic 3 ' with spacer & 500 & 3.5 & 0 \\
\hline Digoxigenin & Solid-phase $3^{\prime}$ and $5^{\prime}$ & 2000 & 10 & 0 \\
\hline DNP & Enzymatic $3^{\prime}$ with spacer & 500 & 3 & 0 \\
\hline DNP & Solid-phase $3^{\prime}$ and $5^{\prime}$ & 500 & 2 & 0 \\
\hline Alkaline phosphatase & Solid-phase & 1000 & 8 & 0 \\
\hline $\begin{array}{l}\text { Alkaline phosphatase } \\
\text { with spacer }\end{array}$ & Solid-phase & 1000 & 3.5 & 0 \\
\hline
\end{tabular}

${ }^{\star}$ ng of oligonucleotide; $\nmid$ scale of 0 to +++ .

\section{PROBE SPECIFICITY}

Specificity of this probe cocktail is well defined and has been confirmed by northern blotting ${ }^{10}$ and in this study by the use of appropriate ISH negative controls. ${ }^{11}$ These were: probe omission, antibody omission, RNAse A1 pretreatment, random oligonucleotide, and nonhomologous probe cocktail with the same G-C content as the histone probe cocktail.

\section{STATISTICAL ANALYSIS}

Cell signal intensities were compared using one-way analysis of variance and Student's $t$ test with the Bonferroni correction.

\section{Results}

IN SITU HYBRIDISATION

All aliquots of labelled probe gave positive results. Sharp, clearly defined NBT/BCIP sites of hybridisation were visible in germinal centres, interfollicular zone, and epithelium. Background staining was negligible in all cases (table 2). Negative controls gave no visible signal on any occasion, this equated to a mean background pixel level of $113 \mathrm{AU}$.

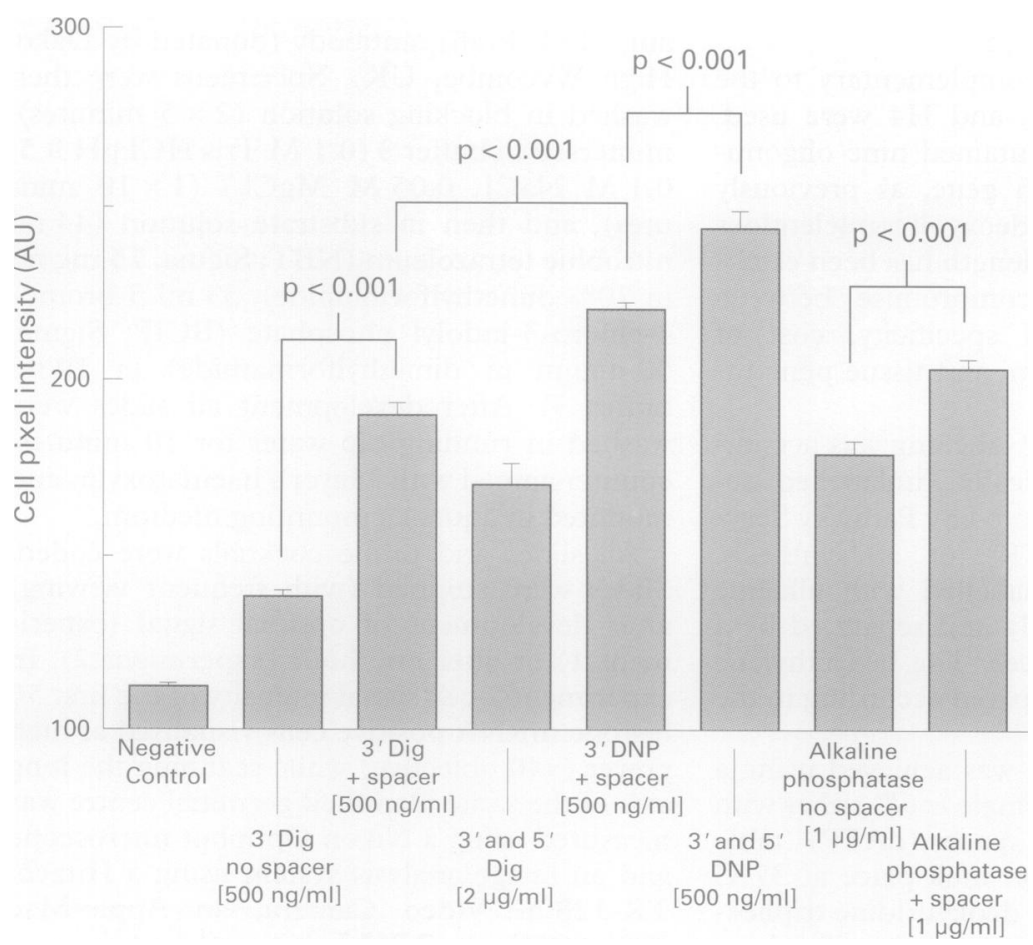

Figure 1 Cell signal intensity in non-radioisotopic in situ hybridisation for histone $m R N A$ in human tonsil. Mean and standard error of values taken from first 50 cells identified in a uniform transection through the dark and light zones of the same germinal centre.

\section{Digoxigenin}

Terminal deoxynucleotidyl transferase 3' labelling with the addition of a nucleotide spacer significantly increased the sensitivity of the ISH reducing the time for optimal development to $<20 \%$ expected (table 2 ) and increasing the cell signal intensity above baseline by 3.2 times $(p<0.001$ ) (fig 1). The use of a spacer allowed a significant reduction in the probe concentration to one fifth that normally required with reasonable maintenance of signal intensity (data not shown). $3^{\prime}$ and $5^{\prime}$ chemical labelling with digoxigenin did not improve the results over 3' labelling with spacer (fig 1).

\section{2,4-dinitrophenyl}

3' labelling with DNP and dATP spacer gave a significantly stronger cell signal intensity than similar labelling with digoxigenin-11-dUTP ( $p<0.001$ ) (figs 1, 2B and C). Furthermore, 3' and 5' chemical labelling with DNP at synthesis produced the strongest signal of all, with approximately a $20 \%$ increase in cell signal intensity over $3^{\prime}$ enzymatic labelling at one hour ( $<<0.001$ ) (figs 1, 2C and D), and correspondingly the shortest incubation time (table 2).

\section{Alkaline phosphatase}

In this study alkaline phosphatase labelled oligonucleotides produced comparable ISH signal as produced by haptens (figs 1 and 2). Inclusion of a hexaethylene glycol spacer between the oligonucleotides and alkaline phosphatase significantly increased ISH signal compared with direct labelling $(p<0.001)$ (figs $1,2 \mathrm{E}$ and $2 \mathrm{~F}$ )

\section{Discussion}

Non-radioisotopic ISH is well recognised as a technique for identifying mRNA species of moderate to high copy number. In these circumstances non-radioisotopic ISH produces a clear definition between positive and negative cells with excellent resolution and preserved morphology. ${ }^{14}$ This is true for paraffin wax embedded, frozen, and decalcified, fresh or archival material. ${ }^{3}{ }^{18} 19$ Furthermore, a strong ISH signal fascilitates double labelling of cells allowing simultaneous cell identification. ${ }^{3} 1819$ However, rarer mRNA species present a much more significant problem to the non-radioisotopic technique particularly with the study of archival material. In this study we considered the nature of the label and its effect on the sensitivity of non-radioisotopic ISH.

The present study provides information concerning the relative efficiency of three oligonucleotide labels; one, digoxigenin, in common use and two, as yet, infrequently used. The data presented suggest that the sensitivity of 3' labelled oligonucleotides for ISH can be significantly improved by the inclusion of a spacer in the labelling reaction. This improvement was maintained even at low probe concentrations. However, chemical $3^{\prime}$ and $5^{\prime}$ digoxigenin did not appear to improve cell signal intensity or development time. In contrast with DNP, there is no commercially available phosphoramidite for the addition of 


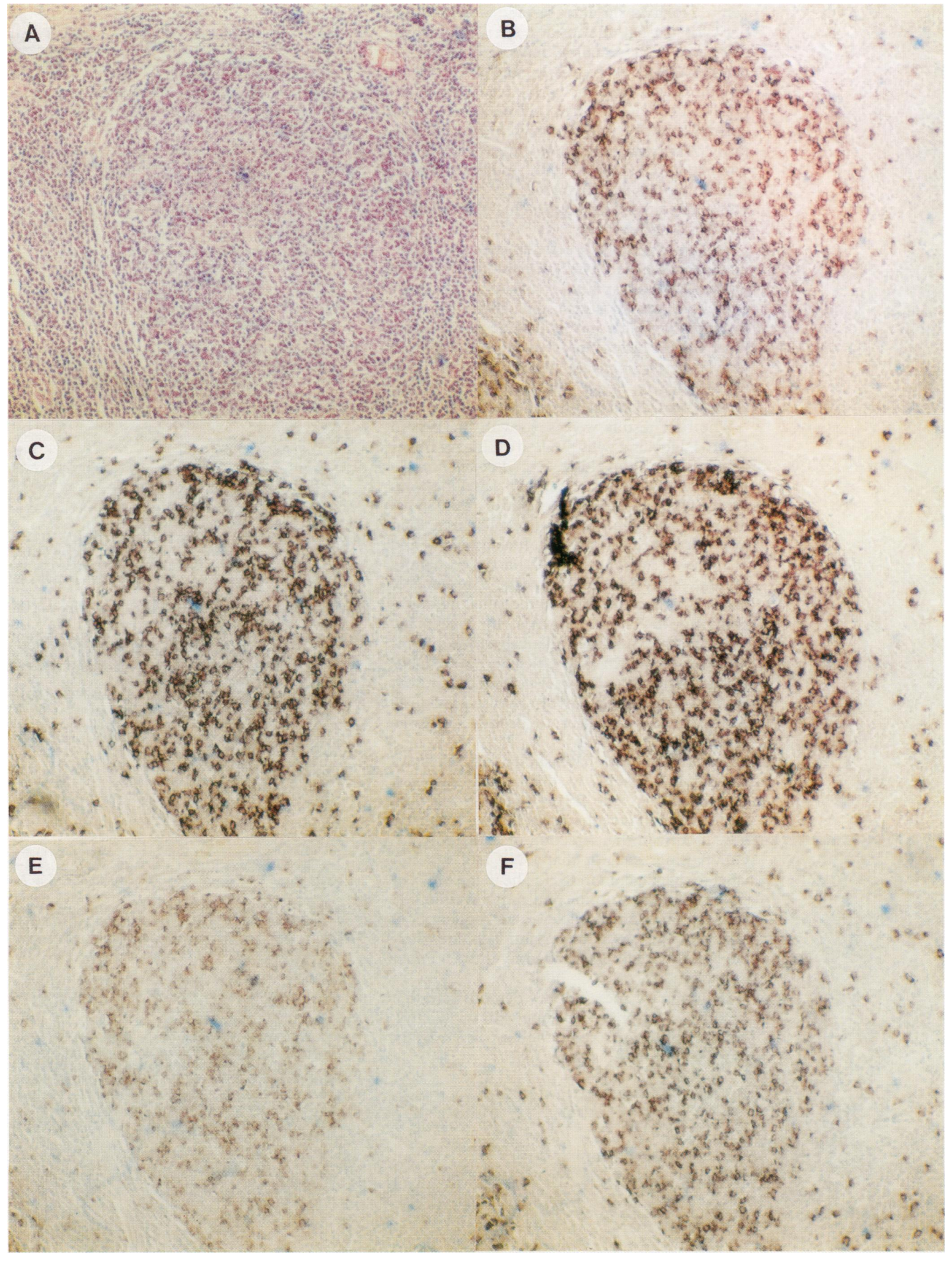

Figure 2 In situ hybridisation demonstration of histone mRNA in tonsillar germinal centre. NBT/BCIP visualisation; haematoxylin counterstain. (A) Haematoxylin and eosin stain; (B) 3' digoxigenin labelling with nucleotide spacer; (C) 3' DNP labelling with nucleotide spacer; (D) $3^{\prime}$ and $5^{\prime}$ chemical DNP labelling; $(E)$ direct labelling of oligonucleotides with alkaline phosphatase; $(F)$ alkaline phosphatase labelling with hydrophilic spacer. 
digoxigenin to oligonucleotides. The digoxigenin moieties have to be added to aminoderivatised oligonucleotides after solid-phase synthesis. The reaction between the digoxigenin derived active ester and the aminofunctionalised oligonucleotide is neither quantitative nor clean. High performance liquid chromatography purification removes the majority of impurities and non-functionalised oligonucleotides, however, for multiple digoxigenin labelling the product is not as homogeneous as the equivalent DNP labelled oligonucleotide.

Oligonucleotides directly labelled with alkaline phosphatase gave comparable results to hapten labels despite the lack of an antibody detection amplification step. Inclusion of a hydrophilic spacer in the alkaline phosphatase label significantly improved the signal. Direct labelling may interfere with hybridisation of nucleotides to target mRNA because of the large size of alkaline phosphatase.

The best results were seen with the hapten DNP. 3' labelling with DNP-dUTP gave better results than 3' labelling with digoxigenin-11dUTP. Furthermore $3^{\prime}$ and $5^{\prime}$ labelling with triple DNP groups gave better cell signal intensity and a shorter development time than any other labelling protocol. In addition, 3 ' and 5 ' chemical labelling provides a large quantity of uniformily labelled probe at a reasonable price. This is in contrast to the labelling of oligonucleotides with haptens by enzymatic methods that produces relatively small quantities and has a variable efficiency. The DNP phosphoramidite monomer used in the present study is structurally similar to those previously reported $^{12}$ but is easier to produce in large quantities.

Previous reports have shown DNP to give comparable results to digoxigenin on test filters $^{7}$ and in the ISH detection of viral sequences and mycobacterial DNA. ${ }^{58}$ We have now used it in the detection of native mRNA. Our findings suggest that DNP is a superior label to digoxigenin in ISH. The increased sensitivity advances routine non-radioisotopic ISH for the detection of nucleic acid sequences of relatively low copy number and facilitates double labelling methods to identify the cell under investigation.

In summary these studies demonstrate that 3 ' and 5' solid-phase labelling with triple DNP reporter groups produce the best labelling for sensitive non-radioisotopic ISH.

EB is supported by the National Kidney Research Fund No R40\2\94. We are grateful to Pathway Services Ltd for the gift of unlabelled oligonucleotides and to Dako for the anti-DNP $\mathrm{F}(\mathrm{ab})_{2}$ antibody.
1 John HA, Birnstiel ML, Jones KW. RNA-DNA hybrids at the cytological level. Nature 1969;223:582-7.

2 Harper SJ, Pringle JH, Gillies A, Allen AC, Layward L, Feehally $\mathrm{J}$, et al. Simultaneous in situ hybridisation of native mRNA and immunoglobulin detection by conventional immunofluorescence in paraffin wax embedded sections. $\mathcal{F}$ Clin Pathol 1992;45:114-19.

3 Harper SJ, Pringle JH, Wicks ACB, Hattersley J, Layward L, Allen AC, et al. Expression of J chain mRNA in duodenal IgA plasma cells in IgA nephropathy. Kidney Int 1994;45: 836-44.

4 Southern EM, Case-Green SC, Elder JK, Johnson M, Mir $\mathrm{KU}$, Wang L, et al. Arrays of complementary oligonucleotides for analysing the hybridisation behaviour of nucleic acids. Nucleic Acids Res 1994;22:1368-73.

5 Stevenson K, Walker CA, Gryzbowski J, Brown T, Sharp JM. Detection of PCR products from Mycobacterium avium subspecies paratuberculosis using oligonucleotides containing multiple 2,4 dinitrophenyl reporter groups. Biomedical Peptides, Proteins and Nucleic Acids 1995;1:17-20.

6 Smith MD, Healy E, Thompson V, Morley A, Rees JL. Use of in situ detection of histone mRNA in the assessment of epidermal proliferation: comparison with the Ki67 antigen and bromodeoxyuridine incorporation. $\mathrm{Br} f$ Dermato 1995;132:359-66.

7 Davison A, Duckworth G, Vaman Rao M, McClean J, Grzybowski J, Potier P, et al. Synthesis and antibody mediated detection of 2,4-dinitrophenyl (DNP) labelled oligonucleotides. Nucleosides Nucleotides 1995;14:1049-52.

8 Cubie HA, Molyneaux PJ, Shearman MJ, Gryzbowski J, Brown T. Dot-blot hybridisation assay for detection of parvovirus B19 infections using synthetic oligonucleotides. Mol Cell Probes 1995;9:59-66.

9 Urdea MS, Warner BD, Running JA, Stempien M, Clyne J, Horn T. A comparison of non-radioisotope hybridisation assay methods using fluorescent, chemiluminescent and enzyme labelled synthetic oligodeoxyribonucleotide probes. Nucleic Acids Res 1988;16:4937-56.

10 Alison M, Chaudry Z, Baker J, Lauder I, Pringle H. Liver regeneration: a comparison of in situ hybridisation for histone mRNA with bromodeoxyuridine labelling for the detection of S-phase cells. $\mathcal{F}$ Histochem Cytochem 1994;42: 1603-8.

11 Jones PH, Harper SJ, Watts F. Stem cell patterning and fate in human epidermis. Cell 1995;80:83-93.

12 Grzybowski J, Will DW, Randall RE, Smith CA, Brown T Synthesis and antibody mediated detection of oligonucleotides containing multiple 2,4-dinitrophenyl reporte groups. Nucleic Acids Res 1993;21:1705-12.

13 Bains MA, Agarwal R, Pringle JH, Hutchinson RM, Lauder I. Flow cytometric quantitation of sequence specific mRNA in hemopoietic cell suspensions by primer induced in situ (PAINS) fluorescent nucleotide labelling. Exp Cell in situ (PAINS) fluo

14 Pringle JH, Ruprai AK, Primrose L, Keyte J, Potter L, Close $\mathrm{P}$, et al. In situ hybridisation of immunoglobulin light chain mRNA in paraffin sections using biotinylated or haptenlabelled oligonucleotide probes. I Pathol 1990;162:197207.

15 Durand M, Chevrie K, Chassignol M, Thuong NT, Maurizot JC. Circular dichroism studies of an oligodeoxyridonucleotide containing a hairpin loop made of a hexaethylene glycol chain: conformation and stability. Nucleic Acids Res 1990;18:6353-9.

16 Pringle JH, Primrose L, Kind CN, Talbot IC, Lauder I. In situ hybridisation demonstration of poly-adenylated RNA sequences in formalin fixed paraffin sections using a biotinylated oligonucleotide poly $\mathrm{d}(\mathrm{T})$ probe. 7 Pathol 1989 158:279-86.

17 Davison A, McClean JM, Vaman Rao M, Brown T. Synthesis of oligonucleotides labelled with 2,4-dinitrophenyl groups at thymidine sites. Biomedical Peptides, Proteins and Nucleic Acids. 1996;2:1-6.

18 Harper SJ, Allen AC, Bene M-C, Pringle JH, Faure G, Lauder I, et al. Increased dimeric IgA-producing B cells in tonsils in IgA nephropathy determined by in situ hybridisation for I chain mRNA Clin Exp Immunol 1995;101:442-8.

19 Harper SJ, Allen AC, Pringle JH, Feehally J. Increased dimeric IgA-producing $\mathrm{B}$ cells in the bone marrow in IgA nephropathy determined by in situ hybridisation for $\mathrm{J}$ chain mRNA. F Clin Pathol 1996;49:38-42. 